\title{
IMPLEMENTING MOBILE COMPUTING EXERCISES BASED ON ANDROID IN CREATING IDEAS TO FACILITATE INDEPENDENCE LEARNING OF READING COMPREHENSION Lusy Tunik Muharlisiani+Anang Kukuh A+Siti Azizah+Dina Chamidah \\ yahdilla@yahoo.com+Anang@anang65.web.id
}

\begin{abstract}
Computer technology has been experiencing a quite rapid development in which it, in turn, has also caused a change in human life style. One of technologies bringing an impact on such life style is in the use of computer technology embedded in mobile communication devices. Nowadays, a new trend in e-learning is known as Mobile Learning, the use of portable media such as smartphone. The main research is argues the need to implement online learning environments to better support the representation and sharing of factual, procedural, to build and develop m-learning that can be used as a flexible learning media and conceptual knowledge in order for students to develop their implement capabilities and produces learning logical reasonable will be prepared based on the needs of development. The implement-based research methodology explicates how implement not only allowed more effective student representation and sharing of the different levels of knowledge required for abstraction to occur, but also enabled better teacher assessment and, hence, remediation also provides detailed guidance on creating interactive content (from the application of learning strategies and media to courseware development). The result obtained from this research is that $95 \%$ of user from university students enjoy in using the application of mobile learning and it is only $5 \%$ does not enjoy. At last, it can be concluded that the use of the mobile learning application can make the learning process more flexible.
\end{abstract}

Key words: Mobile Computing Based on Android, Independent learning and Reading Comprehension

\section{INTRODUCTION}

This research uses the Development and Research method a research to build and develop m-learning that can be used as a flexible learning media. Mobile Computing exercises based on android is a general term used to describe a new class of network based computing that takes place over the Internet, basically a step on form utility. By using the internet and central remote services mobile computing maintains the data, applications which offers much more efficient computing by centralizing storage, memory and processing bandwidth. It can also concentrate on all computational resources and manage automatically through the software without intervenes. Android has been an instant hit and enticing for bountiful users. A multiform applications have been developed but very slender cater the need of the students

The implementation of ICT in educational institution today has been a must since it can be one of indicators for achievement of an educational institution. Many teachers or lecturers use the advance of technology, in this case internet, as online learning also known as e-learning. E-learning (electronic learning) is one of the aspects of the ICT implementation in educational institution. In addition to learning content e-learning can monitor the performance of the college students. A new trend in e-learning nowadays is known as Mobile Learning the use of portable media such as Smartphone either using the Android system, IOS or Windows Phone. The use of Mobile Learning to support the teachinglearning process is considered important to add the flexibility in the activity of teaching and learning. Thus, the learning process can be done anywhere and anytime 
Based on reason above, the researcher provides an overview of online collaborative learning, evaluation methods and learning platforms used to host online courses. This addresses training managers, facilitators and instructional designers who want to know how to conduct, evaluate an online course, how learning platforms can support course delivery, communication among students can increase students' ability in reading comprehension, wants to introduce a powerful tool (mobile computing based on android) and can be used to create a good atmosphere in a class. To achieve a good students' reading comprehension, teachers must implement an effective learning process, namely how to choose the media teaching characteristics according to the needs of students who have different intellectual or talent will help students improve optimum learning outcomes for students. So the teacher can use social media "mobile computing based on android" in teaching learning process as variation because variation will give the students the change of have pleasure in learning language. If teachers do not provide students with the opportunity to represent creative design processes and concepts at the level of structure being addressed then students cannot practise or develop their creative design capabilities and the teacher cannot adequately assess student understanding. Design is a cognitive activity that adds much economic, social and cultural value. Creativity is a desired core competency of individuals and organizations alike. It follows, then, that design and creativity are, or ought to be, among the main goals of learning and teaching. However, we do not fully understand the connections between design and creativity on the one hand, and between learning design, creativity, teaching design and creativity on the other.

Computer technology has rapidly been improving. One of technologies that have brought an impact on this life style is the use of computer technology embedded in mobile communication device. The use of this technology, in fact, can help human in obtaining the update information in many aspects, one of which is in educational aspect. On the other side, the rapid development of science and technology in the form of information and communication technology (ICT) has brought an impact on any fields including in educational and learning field in which the information of learning can be rapidly delivered to all learners through internet. The features of internet technology include being always be accessible anywhere and anytime and capable of involving many users either individually or in a group. In addition, this technology offers all its simplicities. For these features, internet has been becoming a very suitable media for the development of the next education

\section{Problems Examined: during 3 (three) years is presented in Table 1.1}

\section{Objectives and results:}

\section{Identification of the Idea}

a. Designing Computer-Based Exercises with Mobile Computing based on Android

b. Applying Design Computer-Based Exercises with Mobile Computing based on Android Product and Technology

a. The Using of Design Materials CALL Mobile Computing with supporting available

b. The logic of teaching learning design development CALL Mobile Computing based on Android

\section{Formulation of the Problems}

a. How to get packing and storage technology in the design of learning generated

b. How to utilize design learning into various products

c. How to do learning design potential as alternative products 


\section{The Product of Research}

a. The Design Optimization: Teaching Learning CALL mobile computing based on Android and competence-Logic Reasoning

b. The Potential Skimming of Design Learning Materials CALL mobile computing based on Android as alternative products

c. IMPLEMENTATION: Installation and Distribution Managing Learner's Activities,

d. DEVELOPMENT: Second Step: Learning Objectives, Sequencing, Instructional Strategy, Delivery Strategy, Evaluation Strategy

\section{METHODS}

The research method in this research used Development and Research Method, a research to build and develop mobile learning that can be used as a flexible learning media. The steps of the research that can be done are as follows:

\section{START}

Literature Study:

1. Mobile Learning

2. Android Operating System

3. Web Base Technology

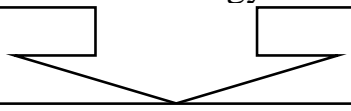

Software Planning

a. Problem Identification

b. Collecting Data

c. Need Analvsis Hardware and Software

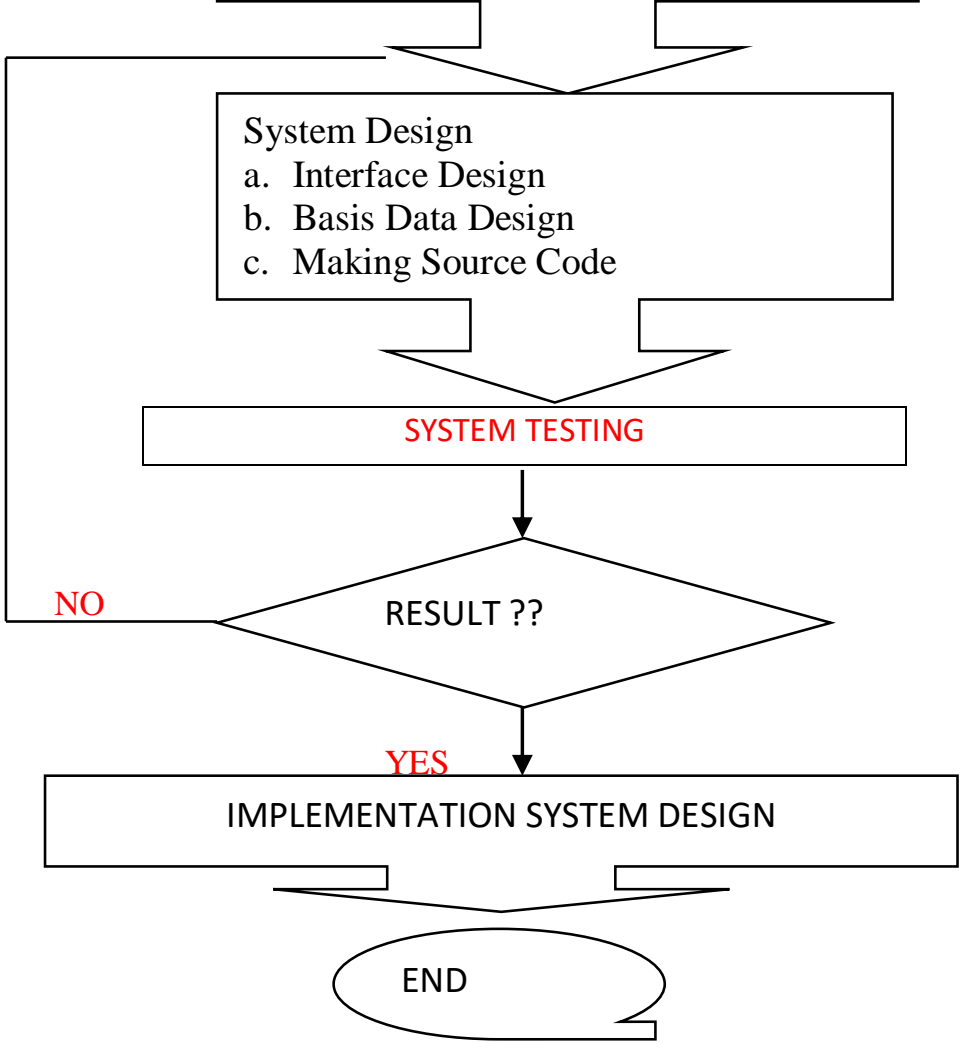


This method emphasizes on an order in the process of software development.

Figure 3.1 Waterfall Method

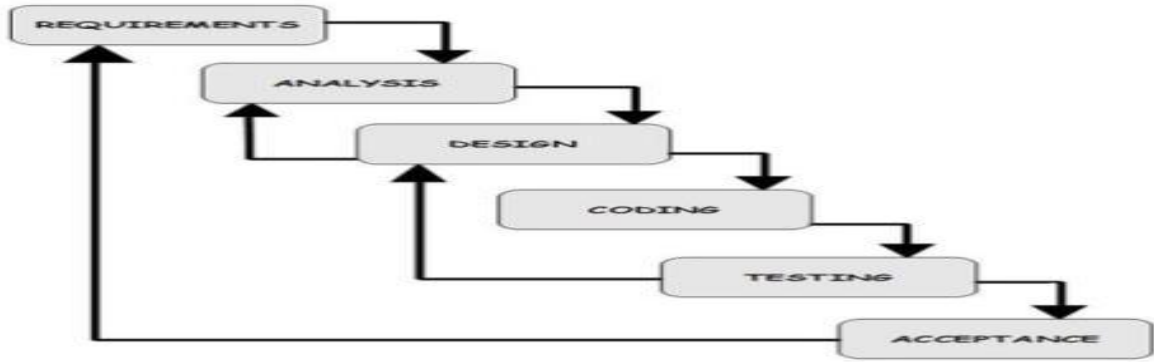

The needs of users on this application consist of system administrator, lecturers, and college students. The Software built will be used by three types of user. Table 3.1 shows the detail of the type. Table 3.1 The Needs of User

User

Administrator

1. Adding the lecturer users

2. Managing system display

Lecturers

1. Adding the materials for lecture

2. Making questions for evaluation

3. Managing the scores for students

Students 1. Downloading the materials for lecture

2. Doing evaluation
Responsibilities

Managing the system comprehensively

Managing the process of online learning

Following the process of lecturing and doing the learning evaluation

The design of interface is aimed to provide the description about the application that will be built. Thus, it can be easy to implement the application. Additionally, it can ease the making of user friendly application. This application can be implemented to be an intact and accessible program. Figure 3.2 shows the design of application interface:
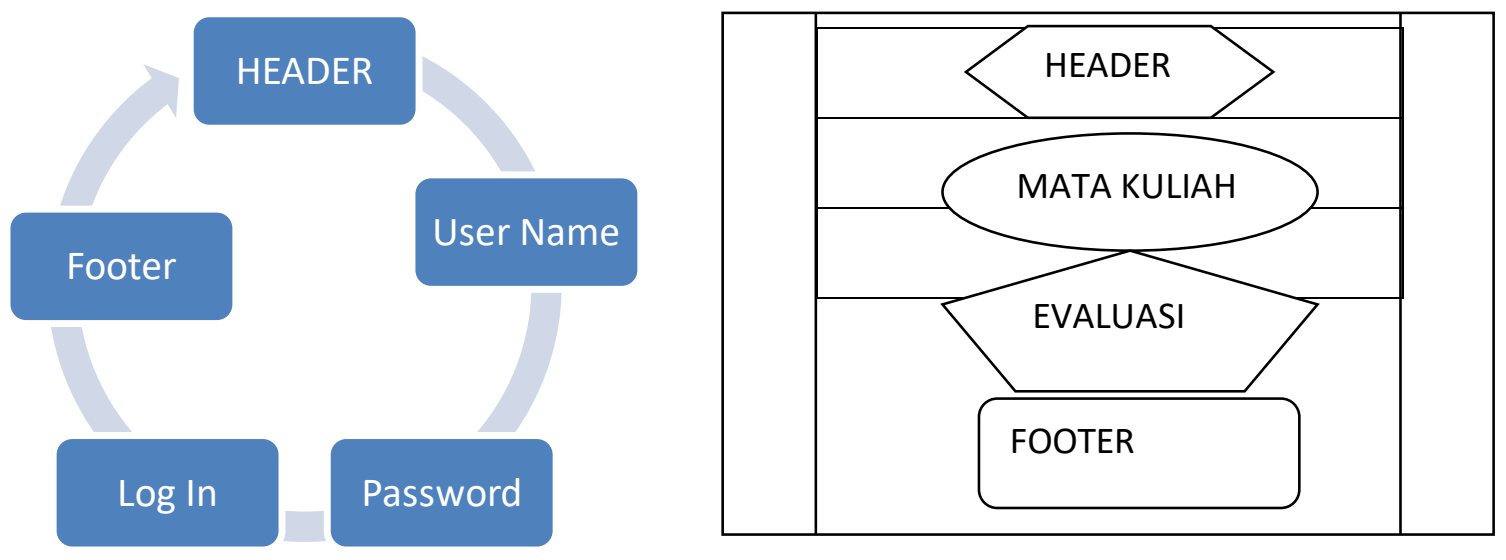

Figure Design of Application Interface

The application test is used to find out the functionality of the system whether it works properly with the design or not. Meanwhile, the implementation testing of the system is conducted using questionnaires that are distributed to 18 college students. 


\section{DISCUSSION}

This part is related to the testing and evaluation of software and implementation of software application. This software is tested based on functionality and performance in the environment of testing at Study Program of Computer System in UWKS.

Testing of Administrator System $\rightarrow$ The first testing is to test the page of administrator on the system of application. The display of dashboard from the page of administrator

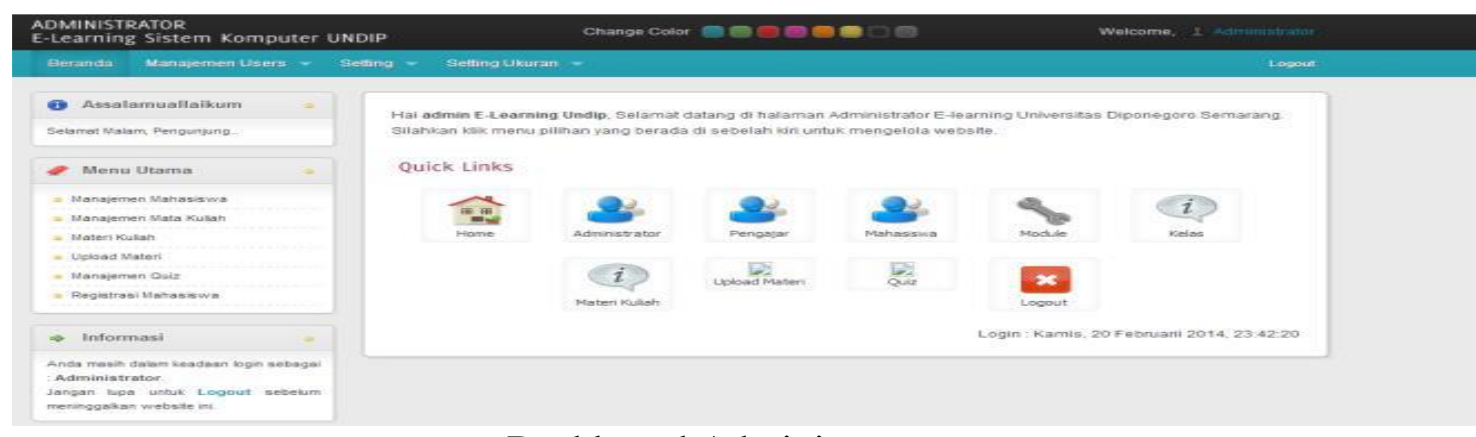

Dashboard Administrator

The next phase is to test the menu of the instructor (lecturers). This is aimed to find out the functionality of the menu that has been developed. Figure 4.2 shows the result of the testing.

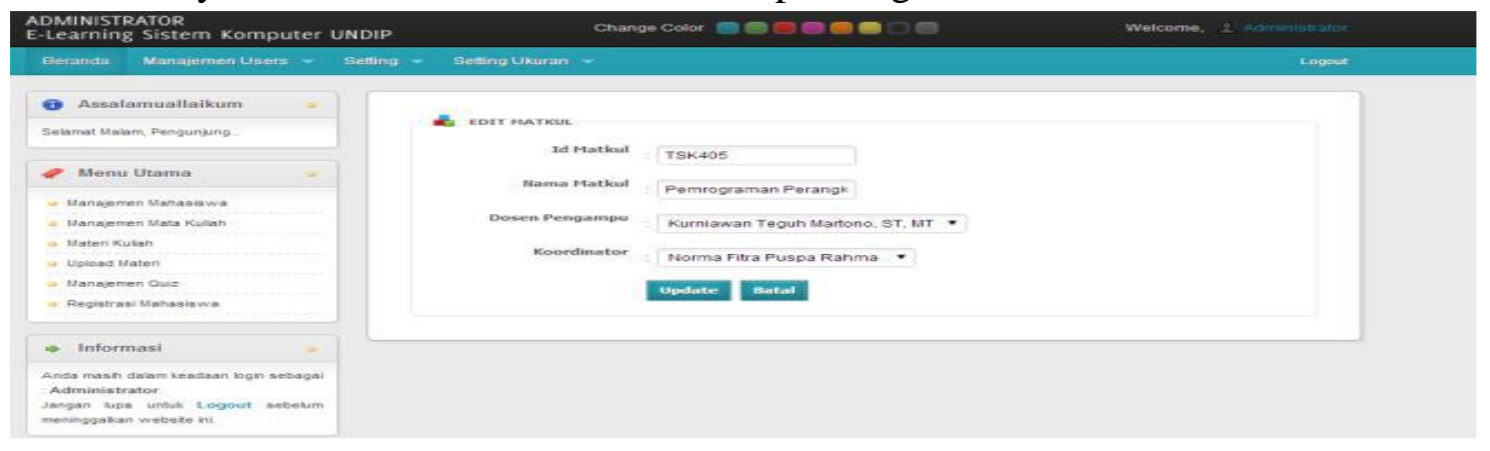

\section{Menu of Instructor (Lecturer)}

\section{Mobile - learning Testing}

The phase of m-learning application testing includes:

1. User installs the application of m-learning on the mobile communication devices.

2. User does login based on the level given

3. User runs application

The testing on the m-learning application performance uses the Black Box testing.

This testing is used to test the functionality of each component in the m-learning system.

Table Shows the Functionality of the testing.

\section{Test Component}

Expected Results

Test Result

Login Page

1. User and password are correct, so it is allowed to go the next page

SUITABLE

2. User and password are incorrect so the message for the incorrectness will appear

Menu Page Showing the menu that can be accessed by the users

SUITABLE

Lecture Page

Download

Material

Showing the list of lecture, lecturer and GBPP

Evaluation Page Showing a number of questions in accordance with the evaluated subjects 
The result of the application test covering the login page, menu page, material download page and lecture page can be seen in Figure Display of M-learning application
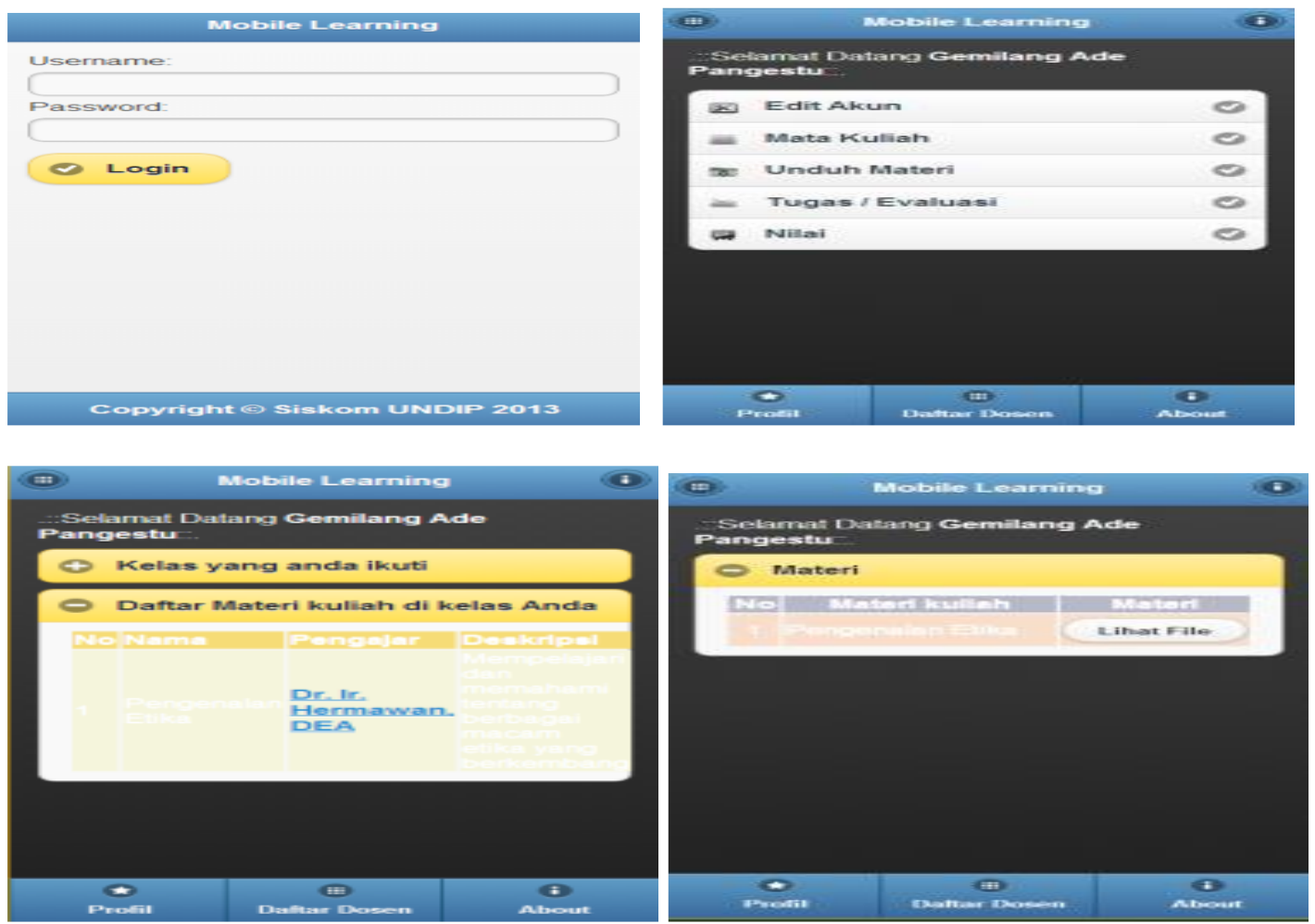

The application of mobile learning can be accessed at http://www.e.learning..uwks.ac.id using the android mobile communication device. To test this application, 18 college students have been involved as the users. The parameters of this test include:

1. Acceleration in accessing the page

2. Acceleration for the login to the system

3. Acceleration for downloading the file of lecture material in PDF form

4. Delivering quiz/evaluation of the lecture

5. Layout of module and material on layout

6. Clear writing size (caption, texts, and typography)

7. Simplicity in the use of navigation

8. The display of interface website design layout for the learning media

9. The displayed features are in accordance with the need of lecture of the parameters of the test given, it is found from the result that $95 \%$ of the user feels comfortable and satisfied in using the application of mobile learning. $5 \%$ of the user, on the other hand, feels uncomfortable in accessing the application of mobile learning. It is due to the problem in telecommunication network used in accessing the mobile learning

\section{CONCLUSION}

Of the parameters of the test given, it is found from the result that $95 \%$ of the user feels comfortable and satisfied in using the application of mobile learning. 5\% of the user, on the other hand, feels uncomfortable in accessing the application of mobile learning. It is 
due to the problem in telecommunication network used in accessing the mobile learningSome conclusions below can be drawn from this research:

1. The application that is made is in accordance with the need of the user

2. Based on the result of the test is found that the software can find out the functions that are incorrect or missing, interface errors, performance error, initialization, and termination error. Functionally, the test has given the result as expected

4. By using the application of mobile learning, the learning process can be more flexible since it can be done anytime, anywhere and in any conditions.

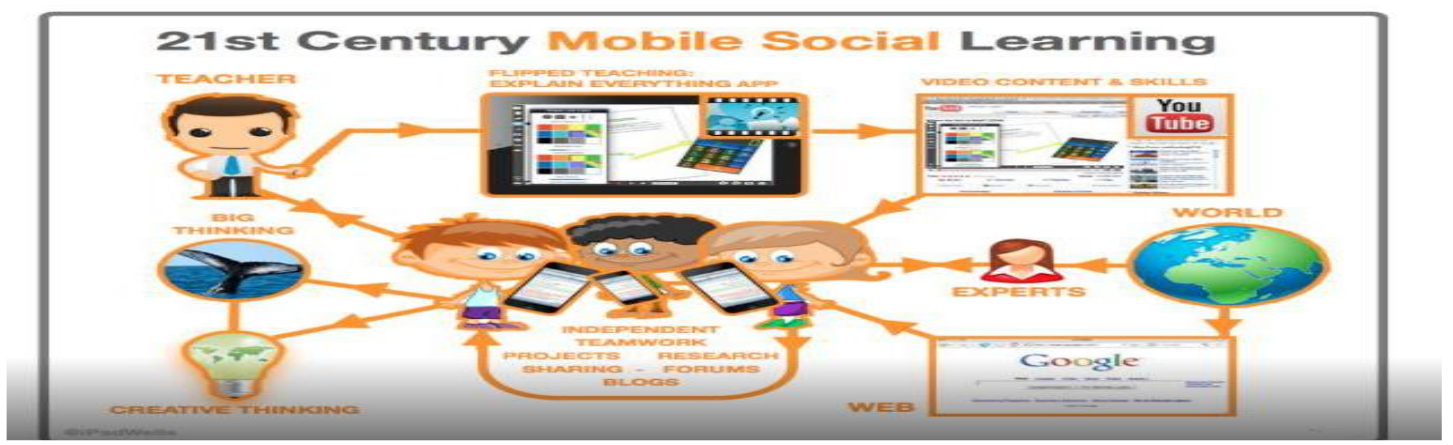

\section{References}

Bower, M (2011) Redesigning Web-Conferencing Environment to Scaffold Computing Students' Creative Design Processes. Educational Technology \& Society, 14 (1), 27-42.

Clark R.C., Mayer R.E., e-Learning and the Science of Instruction-Proven Guidelines for Consumers and Designers of Multimedia Learning, Second Edition, Pfeiffer 2005

Davidson-Shivers, Web-Bassed Learning: Design, Implementation, and Evaluation. New Jersey: Pearson Prentice Hall, 2006.

Gamma, E., Helm, R., Johnson, R., \& Vlissides, J. (2008). Design Patterns: Elements of reusable object-oriented software, Reading, MA: Addison Wesley.

Lee, C.-S, Kolodner, J L \& Goel, A. K (2011) Guest Editorial - Creative Design: Scaffolding Creative Reasoning and Meaningful Learning. Educational Technology \& Society, 14 (1), $1-2$.

M. Rosenberg, E-learning: Strategies for delivering knowledge in the digital age, New York, NY: McGraw-Hill Companies, Inc. 2001, pp. 185-188.

Nurhayati., O. D., "Design of Information Technology in Enhancing the Quality of M-learning -Based Learning at Diponegoro University," International Journal of Computer Science, vol. 10, no. 6, pp. 190-195, .

Pocatilu, P "Developing Mobile Learning Applications for Android using Web Services.," Informatica Economica., vol. 14, no. 3, pp. 106-115, 2010.

See R.E. and Clark, R.C. (2005). e-Learning and the Science of Instruction: Proven Guidelines for Consumers and Designers of Multimedia Learning. 2nd edition. San Francisco: Pfeiffer 